\title{
POLÍTICAS CURRICULARES PARA A FORMAÇÃO DE PROFESSORES ALFABETIZADORES NA DÉCADA DA ALFABETIZAÇÃO
}

Edineia Silva

\section{RESUMO}

Neste trabalho, são investigados os sentidos de alfabetização e letramento presentes nas políticas curriculares para a formação dos professores alfabetizadores, desenvolvidas em nosso país, durante a Década das Nações Unidas para a Alfabetização (2003/2012). Com o objetivo de compreender a pluralidade de sentidos que disputam hegemonia para significar as políticas de formação de professores alfabetizadores, foram feitas pesquisas bibliográficas e análises documentais de dois programas de formação continuada, no âmbito do governo federal: o Programa de Formação do Professor Alfabetizador - PROFA e o Programa PróLetramento e da Reorientação Curricular do Curso Normal - Livro VI elaborada pela Secretaria de Educação do Estado do Rio de Janeiro - SEE/RJ, utilizada nos cursos de formação inicial de professores alfabetizadores. O referencial teórico metodológico pautou-se pelo modelo analítico do Ciclo Contínuo de Políticas proposto por Ball e Bowe (1998). Entre os resultados da pesquisa, destacamos uma multiplicidade de sentidos produzidos nas políticas curriculares, a ampliação de sua articulação discursiva, suas contribuições e possíveis implicações na autonomia do trabalho do professor.

Palavras-chave: Políticas Curriculares. Formação Docente. Alfabetização.

\section{CURRICULUM POLICIES FOR TRAINING TEACHERS IN DECADE OF LITERACY}

\section{RESUME}

Here, we investigated the way literacy and literacy present in curriculum policies for the training of literacy teachers, developed in our country, during the United Nations Literacy Decade (2003/2012). In order to understand the plurality of meanings vying for hegemony to mean the literacy teacher training policies, were made bibliographical research and documentary analysis of two continuing education programs within the federal government: the Teacher Training Program literacy - PROFA and the Pro-Literacy Program and Curriculum Reorientation of Normal Course - Book VI prepared by the Secretariat of Education of the State of Rio de Janeiro - SEE / RJ, used in initial training courses for literacy teachers. The methodological theoretical framework guided by the analytical model of Continuous Cycle Policies proposed by Ball and Bowe (1998). Among the search results, highlight a multiplicity of meanings produced in curriculum policies, the expansion of its discursive articulation, their contributions and possible implications for the autonomy of the teacher's work.

Keywords: Curriculum Policies. Teacher Training. Literacy.

\section{INTRODUÇAO}

Tendo por interesse a investigação dos sentidos produzidos nos currículos da formação inicial do professor alfabetizador, durante a Década da Alfabetização, instituída pela ONU (2003/2012), reafirmo a centralidade da linguagem no contexto das relações sociais porque os 
sentidos construídos sobre alfabetização e, posteriormente, sobre o letramento são partes de uma construção histórica e cultural condicionados por aspectos políticos, sociais e econômicos. Estes são forjados nos contextos em que se situam, não sendo possível pensá-los como verdades apriorísticas com existência independente das relações sociais que os significam ou dependente de um ator que expresse "a pura e universal essência humana" que deve ser perseguida, a fim de alcançar uma "plenitude subjacente a todos os seres".

Os sentidos são produzidos a partir das variadas posições que são ocupadas pelos sujeitos, nas quais concorrem as imbricações de gêneros, classes sociais e etnias. O que confere imprevisibilidade aos sentidos construídos e às suas múltiplas leituras, muito embora tais sentidos tenham uma limitação nas possibilidades de interpretação.

Segundo Pérez (2008, p. 178), "dos ideais humanistas da Reforma Protestante no século XVI à concepção de Alfabetização como Liberdade que informa a Década das Nações Unidas para a Alfabetização da Unesco (2003-2012), verificam-se mudanças significativas no conceito e na forma de praticar a alfabetização". Este artigo destaca os sentidos de alfabetização e letramento utilizados nas últimas décadas e analisa os sentidos hegemônicos presentes nas políticas curriculares de formação de professores alfabetizadores, desenvolvidas durante a Década das Nações Unidas para a Alfabetização.

\section{Sentidos hegemônicos de alfabetização e letramento}

Entre os muitos sentidos atribuídos ao termo, alguns se destacaram hegemonicamente nas políticas curriculares de formação do professor alfabetizador desenvolvidas durante a década em questão. Polarizadas pelas orientações de base construtivista estas políticas vieram ganhando contornos entrecortados por variadas visões sobre o que é alfabetização e como se deve alfabetizar. Nestas disputas estiveram em evidência, no primeiro momento, a alfabetização entendida como construção do sujeito cognoscente, baseada nas influências da epistemologia genética utilizadas por Emília Ferreiro e Ana Teberosky (1985); e, posteriormente a especificação dos termos alfabetização como aquisição do sistema de escrita e o letramento, entendido como estado ou condição que assume aquele que aprendeu a ler e escrever. Ambos os termos entendidos como distintos e com suas especificidades, porém, complementares entre si. Esta proposição foi defendida por Magda Soares (2003).

As mudanças ocorridas a partir da década de 1980, com os resultados das pesquisas de Ferreiro, trouxeram como desafio a busca de novos paradigmas que pudessem balizar as metodologias de alfabetização que, até então, se assentavam nos métodos sintéticos e analíticos partindo do pressuposto de que a alfabetização era a aquisição de um código pronto, transposto de fora para dentro. Essas mudanças conhecidas como processo de desmetodização da alfabetização trouxeram consigo muitas inquietações à prática pedagógica dos professores. Das orientações explícitas sobre o "como fazer", indicando o passo a passo que deveriam seguir, os professores se veem orientados por outro paradigma que se baseia na construção e reconstrução diária da prática pedagógica. Sem modelo único, sem receitas prontas.

Ainda neste período, surge como modelo teórico nas disputas hegemônicas a abordagem discursiva do processo de alfabetização, proposto por Smolka. Entendendo a leitura e a escrita, não como algo que simplesmente "se aprende" ou "se ensina", mas como uma forma de interação, uma forma de linguagem, a autora defende a ideia de que o discurso egocêntrico revela a elaboração do discurso interior. Ela toma como pressuposto a teoria vigotskiana, que diz que "o discurso egocêntrico da criança é uma forma de processar o discurso social e constitui, fundamentalmente, um período de transição do 'discurso social' externo para o 'discurso interior'" (SMOLKA, 2012, p. 89). Uma das preocupações de seus 
estudos é tentar entender como se relacionam o discurso interior e o discurso escrito e suas implicações no processo inicial de leitura.

Os resultados das avaliações em larga escala na década de 1990, favoreceram ainda mais o emaranhado de divergências e posições teóricas onde foram reacesos os embates entre as propostas construtivistas e o método fônico (abordagem sintética). Ainda que distante do discurso oficial, o método fônico esteve presente no ideário e na prática de muitos professores ao longo do século XX e, continua, até os nossos dias, como podemos constatar nas pesquisas de Morais (2006). Ele dá a sua maior ênfase à associação entre letras e fonemas em detrimento de sentidos mais substanciais do texto.

A atualização deste debate se dá quando Capovilla (2003) apresenta o relatório "Os novos caminhos da alfabetização infantil" encomendado pela Câmara dos Deputados, em Brasília, ao Painel Internacional de Especialistas em Alfabetização Infantil. Ao valer-se da "Ciência da Leitura" como legitimadora das proposições feitas, esse discurso busca conferir status de "verdade inquestionável" a ser considerada por políticos, pesquisadores e profissionais da área. Cabe questionar, seguindo as bases de análise de matriz pósestruturalista, as limitações das verdades essencializadas, que não podem dar conta da tarefa de alfabetizar crianças, em todos os tempos e lugares, atendendo aos mais diferentes propósitos e concepções sobre o que é alfabetização e como deve ser realizada.

O Brasil que vive, hoje, a caótica situação de ter apenas $25 \%$ da população alcançado a alfabetização em nível pleno, como registram os dados do INAF (2011), arrasta uma dívida secular com seu povo, de exclusão da participação social, política, econômica e dos bens culturais. Essa dívida tende a se agravar na medida em que, cada vez mais tardiamente, a escola se comprometa com práticas de leitura e escrita que encarem com seriedade os seus significados políticos e potencializador. Penso ser um retrocesso a desconsideração da capacidade humana de produzir sentidos que se revelam na cultura, a partir de sua experiência no grupo social.

No bojo dessas discussões, Morais, Albuquerque e Leal (2005), organizaram um subsídio teórico para o Ministério da Educação e Cultura - MEC, com o título "Alfabetização: apropriação do sistema de escrita alfabética". Os textos retomam questões como a reflexão sobre as unidades menores que compõem o nosso sistema de escrita (letras, sílabas e palavras).

Abre-se a possibilidade de diálogo com alguns pressupostos literalmente excluídos dos discursos oficiais sobre alfabetização após a década de 1980. Os autores deixam claro, porém, que não propõem a defesa da volta dos "velhos métodos"; embora considerem desejável e necessário o ensino sistemático do sistema de escrita alfabético. Há uma proposição de que a alfabetização, entendida como aquisição do código alfabético, caminhe paralelamente ao processo de letramento, entendido como a possibilidade de fazer uso social da leitura e da escrita; isto é, alfabetizar letrando.

Esses sentidos que foram se construindo ao longo do tempo formaram os arcabouços sobre os quais foram se constituindo as políticas curriculares de formação de professores alfabetizadores durante a Década da Alfabetização instituída pela ONU (2003/2012). As disputas, as negociações e os consensos foram fixando provisoriamente os seus significados, caracterizando o que Ball (1998) descreve como peculiaridade deste processo, ou seja, diversos interesses vão se estabelecendo hegemonicamente, de forma contingencial, de acordo com as relações de poder que entram em jogo. Nesse cenário, a política é compreendida para além da produção e implementação, mas como um processo dinâmico que funde estas duas dimensões em todos os âmbitos em que ela se desenvolva, seja no contexto de influência, onde se definem os fins da educação; seja no contexto de produção, onde se 
produzem os textos, as teorias que vão embasar estas políticas; ou seja no contexto da prática, nas salas de aula onde os professores atuam. Em outras palavras, todos participam deste processo.

\section{Alfabetização e Letramento nas políticas de formação continuada}

Os documentos do Programa de Formação do Professor Alfabetizador-PROFA e do Programa Pró-Letramento, ambos do governo federal e a Reorientação Curricular da disciplina de Abordagem Psico-Sociolinguística do Processo de Alfabetização, utilizada na formação inicial do professor alfabetizador pelo governo do Estado do Rio de Janeiro foram selecionados para análise por representarem as principais políticas que serviram de referência para o encaminhamento da prática pedagógica na formação do professor alfabetizador.

O PROFA foi um programa de formação continuada de professores alfabetizadores, desenvolvido pelo Ministério da Educação, na gestão do então presidente Fernando Henrique Cardoso e tendo à frente da Educação, o ministro Paulo Renato de Souza. Segundo o Relatório da Gestão Financeira (BRASIL, 2001) deste ministério, o programa atingiu 1.188 municípios dos 5.561 municípios brasileiros, em 20 estados brasileiros. Foram formados 75.436 professores, distribuídos em 169 núcleos de atendimentos. No Rio de Janeiro, foram atendidos 31 dos seus 92 municípios. Conforme se percebe, foi um programa ousado para a condição ainda incipiente da experiência em formação continuada no âmbito nacional, porém de abrangência pouco expressiva para as nossas dimensões continentais.

Em seu Guia de Orientações Metodológicas encontramos 196 páginas dedicadas à metodologia de formação dos formadores. No documento, encontramos a seguinte afirmação:

A formação profissional - embora em geral não a tomemos dessa forma - é um processo de educação de adultos, um processo de ensino e aprendizagem em que adultos aprendem com adultos os conteúdos relacionados, direta ou indiretamente, ao exercício de uma profissão. Não basta, portanto, simplesmente transferir os modelos de ensino e aprendizagem escolar para a formação de professores, por melhor que sejam. Não basta tratar os professores como alunos que aprendem conteúdos cujo uso não é imediato e nem contextualizado. Não basta organizar as ações tendo como apoio exclusivamente a informação teórica sobre a prática pedagógica. Não se pode tomar o exercício do magistério simplesmente como aplicação e manejo de um conjunto de técnicas, pois a atuação de professor é complexa e singular. É preciso recriar as formas convencionais de ensino e aprendizagem para torná-las adequadas às peculiaridades da formação de professores (BRASIL, 2001, p. 13).

Compartilho a ideia de que o investimento profissional na formação dos formadores de professores deva ser criterioso e sensível para perceber as peculiaridades que envolvem esta formação. Ainda que esta se oriente por princípios coincidentes com o referencial utilizado com as crianças, penso que precisamos nos aprofundar em estudos que possam subsidiar as nossas práticas para direcioná-las a esse público-alvo com suas especificidades. Considero que o PROFA traz essa contribuição, na medida em que abre a perspectiva do olhar sobre essa formação. 
O Programa se justificou pela "necessidade de oferecer aos professores brasileiros o conhecimento didático de alfabetização, que vem sendo construído nos últimos vinte anos" (BRASIL, 2001, p.5), anteriores à sua publicação. A ênfase reforça as preocupações surgidas com o desenvolvimento do construtivismo, que trouxe muitos desafios ao professor alfabetizador. Em seu documento de apresentação, ele assume que, apesar dos diferentes sentidos atribuídos ao termo alfabetização, no âmbito do programa, o termo consiste na "aprendizagem do sistema alfabético de escrita" (BRASIL, 2001, p.7).

O Programa desenvolve dois conteúdos centrais: 1) como acontecem os processos de aprendizagem da leitura e da escrita e 2) como organizar, a partir desse conhecimento, situações didáticas adequadas às necessidades de aprendizagem dos alunos e pautadas na metodologia de resolução de problemas.

O desafio consiste em organizar as propostas didáticas a partir do que hoje se sabe a respeito de como se aprende, instaurando uma cultura escolar centrada no direito à aprendizagem. Para assegurar este direito aos alunos é indispensável que os professores tenham assegurado o seu direito de aprender a ensinar e esta tarefa cabe às instituições formadoras. Esta proposição feita no programa traz para o debate as marcas da ambiguidade, pois, se por um lado é desejável que alunos e professores tenham o direito de aprender, é questionável saber quem vai "conceder" este direito e com qual interesse. Longe de ser uma questão simples de ser respondida é uma questão que exige que se viva essa constante tensão; pensar uma mesma questão a partir de lógicas contraditórias.

A afirmação de que "a resolução de situações-problema tornou-se a estratégia metodológica principal das situações de ensino-aprendizagem" (BRASIL, 2001, p. 14) e os relatos reflexivos feitos por educadores sobre suas práticas de formação deixam de ser itens ilustrativos, como habitualmente ocorre, para se tornarem de fato os conteúdos, por excelência, dos capítulos do subsídio.

Entre os sentidos de alfabetização e letramento identificados no programa, destacamse: a alfabetização como ensino e aprendizagem do sistema alfabético de escrita e com orientação pautada pela epistemologia genética, segundo a Psicogênese da Língua Escrita de Emília Ferreiro e Ana Teberosky (1985). Essa abordagem apareceu de forma pormenorizada ao longo dos capítulos das coletâneas de textos para o trabalho com os professores, aprofundando cada aspecto da temática. A abordagem discursiva do processo de alfabetização apareceu subentendida, trabalhada apenas de maneira superficial, sem ênfase em seus pressupostos teóricos. O letramento apareceu como expectativa de aprendizagem do curso em relação ao professor cursista, embora não se tenha feito alusão extensiva ao tema de forma mais explícita. Não houve nenhuma menção ao trabalho com a consciência fonológica, embora tenham sido trabalhados alguns textos de Morais (2001) relativos à ortografia. São percebidas nuances e esboços dos discursos sobre letramento, abordagem discursiva do processo de alfabetização sem, contudo, representar um maior enraizamento no escopo do programa.

O programa Pró-Letramento (2005) foi elaborado no âmbito da Rede Nacional de Formação Continuada, durante o governo do presidente Luís Inácio Lula da Silva. Ele foi dedicado aos professores em exercício das séries iniciais do ensino fundamental. Foi realizado pelo MEC (SEB/SEED), Universidades Parceiras (Centros de Pesquisa e Desenvolvimento da Educação), com adesão de estados e municípios, sem obrigatoriedade para os professores, e, integrou ações da "Mobilização pela qualidade na educação", movimento da sociedade civil brasileira em prol de uma Educação Básica de Qualidade Para Todos. Segundo Orofino (2010) o lançamento do programa Pró-Letramento no Estado do Rio de Janeiro ocorreu em setembro 
de 2006. A Secretaria Estadual de Educação do Estado do Rio de Janeiro foi articuladora entre as Universidades e as Secretarias Municipais de Educação.

O programa teve como objetivos: oferecer suporte à ação pedagógica de professores, das séries/anos iniciais, elevando a qualidade do ensino e da aprendizagem em Língua Portuguesa e Matemática; incentivar a reflexão e a construção de conhecimento como processo contínuo de formação de professores; e, contribuir para o desenvolvimento da cultura de formação continuada em rede. Cada unidade apresentada no documento ficou a cargo de um dos Centros de Linguagens vinculados às Universidades parceiras que compunham a Rede.

O programa optou por fazer a distinção entre os termos alfabetização e letramento lidando com estes dois conceitos em sua abordagem diferencial, porém interdependentes, aconselhando um trabalho que os integre simultaneamente. Esta opção refletiu as influências do CEALE - Centro de Alfabetização, Leitura e Escrita da Faculdade de Educação da UFMG fundado por Soares, em 1991.

O Pró-letramento destacou as potencialidades encontradas nos diversos métodos de alfabetização tradicionalmente utilizados e apontou as omissões encontradas que podem acarretar prejuízos na aquisição da leitura e da escrita. Desta forma, veio elencando o método silábico, os métodos fônicos, os métodos analíticos, as práticas construtivistas e o letramento como propostas que precisam ser mais criteriosamente analisadas, para que não se perca de vista a contribuição que cada uma pode oferecer em cada momento específico.

Ao reabrir esta vasta possibilidade de coexistência de diversas matrizes teóricas, o programa assume características bem distintas do que vinha sendo feito em termos de políticas curriculares para alfabetização. Há uma abertura para a articulação e o consenso provisório entre as diferentes demandas referentes à construção do conceito de leitura e escrita, a aquisição e sistematização do código alfabético, a consciência fonológica, ao letramento e a abordagem discursiva do processo de alfabetização.

Estas, embora não apaguem suas diferenças, são negociadas tornando a articulação das mesmas, discursivamente possível no texto da política. Para justificá-la, o texto diz que "o estágio atual dos questionamentos e dilemas no campo da educação nos impõe a necessidade de firmar posições consistentes, evitando polarizações e reducionismos nas práticas de alfabetização" (BRASIL, 2008, p. 11). Os autores iniciam o primeiro fascículo levando o leitor a refletir sobre os prejuízos dos posicionamentos radicais em relação às opções metodológicas.

Esse processo traz para a alfabetização novas perspectivas na configuração da prática pedagógica, na medida em que legitima o consentimento de uso das várias matrizes teóricas em jogo e alarga o espaço para infinitas composições que o professor pode fazer para construir a sua prática. Fica evidenciado na exposição dos autores um processo de equívocos e mal-entendidos na compreensão dos métodos, apontando para a necessidade de retomada dos mesmos, a partir de uma releitura por novos parâmetros. Concordo com o posicionamento destes autores e reafirmo que a ampliação do leque de opções do professor para construir sua prática implica no respeito à sua autonomia.

$\mathrm{Na}$ definição do documento entende-se alfabetização em seu sentido restrito de aprendizado inicial da leitura e da escrita, da natureza e do funcionamento do sistema de escrita, e entende-se letramento como práticas sociais de uso da língua escrita. Faz-se a proposta de alfabetizar letrando.

O programa traz como possibilidade o desenvolvimento das capacidades linguísticas de ler, escrever, ouvir e falar com compreensão, em situações diferentes das familiares, são sugeridos eixos em torno dos quais estas capacidades estão organizadas: 1) a compreensão e a 
valorização da cultura escrita, 2) a apropriação do sistema de escrita, 3) leitura, 4) produção de textos escritos, 5) desenvolvimento da oralidade.

As concepções relativas à avaliação, enfatizam a sua dimensão formativa com função diagnóstica, processual, descritiva e qualitativa, a serviço das orientações das aprendizagens dos alunos, em detrimento de sua dimensão técnica que tem como função a regulação dos recortes dos tempos escolares, apresentando um caráter classificatório.

No texto da política, a avaliação formativa, como reguladora e orientadora do processo de aprendizagem, comporta duas funções avaliativas inseparáveis, a função diagnóstica e de monitoramento. A função diagnóstica tem como objetivo conhecer cada criança e o perfil da turma em relação ao seu desempenho, seus progressos e suas dificuldades; a função de monitoramento acompanha e intervem na aprendizagem para orientar o ensino e resgatar $o$ sucesso dos alunos.

Apesar das orientações criteriosas em relação ao processo formativo no âmbito escolar, têm sido muito polêmicas as discussões sobre a avaliação externa realizada em larga escala. 0 Pró-Letramento trouxe os primeiros desenhos dessa proposição para a alfabetização. Dotado de uma matriz de referência com conhecimentos e competências pré-definidas sobre o que o aluno deve ter adquirido ou desenvolvido ao final do 20 ano de escolaridade, o debate em torno desta temática passa pelo questionamento profundo aos processos que legitimam as desigualdades no acesso ao conhecimento, a partir de referenciais homogeneizadores, que não consideram a pluralidade de sujeitos e seus condicionantes na relação ensino e aprendizagem. Outro aspecto da discussão são as questões relativas ao conceito de alfabetismo. Ao entendê-lo como a capacidade de atuar funcionalmente no contexto social são questionadas quais capacidades têm sido tomadas como parâmetros para definir quem está ou não alfabetizado e em que nível.

As proposições apresentadas nos fascículos abordam questões que ampliam os ângulos pelos quais podemos pensar as questões relativas à alfabetização e ao letramento, tais como: os tempos da leitura e da escrita em sala de aula, o planejamento da rotina escolar, a biblioteca escolar, o trabalho com o lúdico, as questões que envolvem o livro didático e os modos de falar e modos de escrever. No fascículo complementar, são feitas reflexões sobre as atividades relacionadas à identidade como possíveis contribuições ao desenvolvimento linguístico, afetivo e social do aluno.

Podemos dizer que o Pró-Letramento foi um programa que trouxe contribuições importantes quanto ao aprofundamento de questões relativas ao processo de alfabetização e letramento da população brasileira, na medida em que articulou um número maior de demandas políticas fazendo uma abordagem multidimensional sobre o tema.

Apesar de inserir diversas matrizes teóricas, a partir de novas leituras, o texto não enfatiza de forma explícita a abordagem discursiva do processo de alfabetização. 0 material impresso do programa diz pouco sobre o seu percurso de construção. Os processos de avaliação externa aparecem fortemente atrelados às finalidades do programa que traz no seu conteúdo as matrizes de referência da avaliação diagnóstica.

Apesar das polêmicas que dividem as opiniões entre os que defendem e os que denunciam as avaliações em larga escala, acredito que é preciso avaliar. Qualquer processo social prescinde de ser avaliado, inclusive a própria avaliação, também precisa ser avaliada. É importante responder sobre: O que avaliar? Como avaliar? Por que avaliar? E, sobretudo, o que fazer com os resultados da avaliação? Embora a avaliação não seja o foco deste trabalho, é importante perceber o quanto estas questões têm implicações sobre a visão, as escolhas e as prioridades do professor alfabetizador, orientando sentidos em relação a sua própria prática pedagógica. 


\section{Alfabetização e Letramento na política de formação inicial}

A Reorientação Curricular - Livro IV (SEE/RJ,206) traz de forma concisa a organização curricular pretendida para todas as escolas de Curso Normal do Estado do Rio de Janeiro. $\mathrm{Na}$ introdução, o documento enfatiza que o currículo da escola deve ser elaborado a partir do seu Projeto Político Pedagógico e afirma:

Este currículo deve incorporar informações concretas sobre o que ensinar, como ensinar, quando ensinar, como, por que e como avaliar este ensino. Um currículo, portanto, incorpora conceitos e conteúdos, mas não só: como dirige as atividades educativas da escola como um todo, os valores que as sustentam também devem estar nele contempladas.

Ao currículo precisam ainda ser associados os programas curriculares, organizados por área de conhecimento, por disciplinas, por série. Estes programas devem possuir uma ordem lógica, que respeite a epistemologia da área de conhecimento, e apresentar claramente as opções metodológicas e conceituais.

[...] Do ponto de vista de sua organização, os componentes do programa curricular devem ser: os objetivos para a aprendizagem, as estratégias de ensino, uma visão comum sobre processos de aprendizagem e a interação entre estes e os materiais didáticos selecionados como suporte do trabalho cotidiano (SEE/RJ, 2006, p. 16).

Na proposta, o currículo é concebido dentro de uma racionalidade técnica que enfatiza os conhecimentos científicos como os conteúdos por excelência que devem ser ensinados, passando ao largo de sua abordagem a consideração de aspectos relativos às implicações das questões culturais no currículo. Ele propõe o reconhecimento das diferenças como o que elas são: diferenças, e, a sua superação garantindo a todos os estudantes o direito à formação ativa, criativa, de qualidade, que incorpore o uso de diversas linguagens, a compreensão de conceitos, princípios, relações e fenômenos nas diferentes áreas do saber, que os permita compreender a realidade à sua volta e fazer escolhas acerca de valores e princípios éticos. Ao propor a "superação" das diferenças e um conjunto de conceitos, princípios, relações e fenômenos, a organização curricular deixa transparecer uma crença em uma cultura e um conjunto de conhecimentos considerados universais e capazes de dar conta de todas as realidades sociais a que ele se destina.

O documento ainda propõe "que as escolas normais assumam o desafio de articular formação geral e específica, problematizando as disciplinas que compõem a base nacional comum do ensino médio com o olhar de como se ensina e como se aprende cada uma delas". (p. 29).

Em relação ao papel da disciplina Abordagem Psico-Sociolinguística do processo de Alfabetização na formação de professores e suas demandas, são descritas como tarefas da disciplina: garantir que os futuros professores possam ter acesso à teoria produzida na área da alfabetização; incentivar a formação de professores pesquisadores da própria prática, 
valorizando os saberes dos alunos, tomando-os como ponto de partida para o diálogo necessário entre a leitura de mundo e a leitura da palavra. Existe a compreensão de que "a alfabetização, no espaço escolar, é uma prática que se constrói na interação entre sujeitos históricos (alunos/alunos; alunos/professores), articulada em torno de objetos culturais socialmente produzidos (leitura e escrita), em um movimento dinâmico e vivo, através da troca de experiências, de vivências concretas e de um processo permanente de reflexão sobre o conhecimento" (p. 125).

A organização da disciplina de forma aparentemente contrária às orientações gerais do documento inclui em sua prática a valorização dos saberes dos alunos e reconhece o processo dialético de construção desta prática. Elenca-se como conhecimentos necessários ao futuro professor das séries iniciais os processos de permanência e mudança na alfabetização, os altos índices de analfabetismo, fracasso e evasão escolar, concepções de alfabetização, os métodos e processos de desenvolvimento e aprendizagem da leitura e escrita, processo de construção do conhecimento, as teorias que embasam as concepções de aprendizagem, a história da escrita e seus códigos, a oralidade como parte integrante das práticas alfabetizadoras, 0 caráter discursivo da alfabetização, ambientes alfabetizadores e o papel do lúdico, a avaliação numa perspectiva formativa do sujeito.

A Reorientação Curricular do Curso Normal tem orientação pautada pela epistemologia genética que é identificada no discurso das práticas alfabetizadoras com grande influência, segundo os estudos da Psicogênese da Língua Escrita de Emília Ferreiro (1985). O caráter discursivo do processo de alfabetização é reconhecido e apontado como tópico dentro do bloco de conteúdos que analisa as relações entre a linguagem oral e a linguagem escrita, sem representar, explicitamente, um eixo na estrutura geral do trabalho. A formação do professor pesquisador a partir de sua prática se apresenta na disciplina de Prática Pedagógica. Não se faz presente no documento a alusão ao desenvolvimento da Consciência Fonológica. Na descrição dos conhecimentos necessários e na ementa da disciplina não aparece inicialmente o termo letramento, este só aparece nas referências bibliográficas com a indicação do livro de Magda Soares: "Letramento - Um tema em três gêneros" (1998); pela portaria SEEDUC/SUGEN 91/2010 é incorporado o termo ao nome da disciplina, passando a ser chamada de Processos de Alfabetização e Letramento.

As propostas curriculares para a formação inicial e continuada de professores alfabetizadores são constituídas por particularidades defendidas por grupos distintos, que participam das disputas para significá-las. Ao que se percebe, proposições referentes à alfabetização, como aquisição do código escrito, e, letramento, como uso social da língua, embora tenham divergências conceituais, não afetam suas bases epistemológicas. Se juntarmos a elas a demanda referente aos aspectos discursivos do processo de alfabetização, teremos três demandas que brigam pela defesa de seus espaços, mas que se alinham em seus propósitos, atuando de forma complementar entre si. As propostas pautadas no método fônico representam crenças e valores diametralmente opostos em relação ao grupo anterior, chegando a negá-los em seus argumentos; e a defesa por metodologias que levem em conta a consciência fonológica e a sistematização de aspectos do SEA associadas à ideia de alfabetização como construção conceitual e ao letramento articula um conjunto de pressupostos para pensar o processo de alfabetização.

Considero um avanço a abertura para a incorporação de diversos matizes teóricos na política do programa Pró-Letramento. A simples transmutação de uma perspectiva teórica para uma política curricular de formação de professores alfabetizadores, tal como nos sinaliza Mortatti (2008) ao fazer a retrospectiva histórica desta formação reduz as múltiplas possibilidades de produção de sentidos para a prática alfabetizadora. 
As articulações feitas nas políticas curriculares, enquanto práticas de letramento situadas historicamente, refletem as negociações possíveis entre sentidos de alfabetização. $\mathrm{Na}$ perspectiva do letramento, em caráter revolucionário, é possível analisar como estas práticas problematizam as ordens estabelecidas favorecendo a autonomia de escolhas para a construção da própria prática; ou servem para reduzir as possibilidades de escolhas enquadrando uma suposta autonomia aos limites do já escolhido; evidenciando uma prática que ajuda a perpetuar valores e crenças que perpassam as relações de poder na construção dos currículos escolares. Tal proposição pode nos levar aos limites do risco do indesejável, mas também pode, radicalmente, nos expor ao alcance da maturidade profissional que se adquire por meio da apregoada autonomia, exaustivamente citada em documentos nacionais e internacionais de referência para a formação de professores, e tão pouco observada nos modelos curriculares que partem das escolhas prévias.

\section{CONCLUSÕES}

A análise geral das políticas curriculares aponta para alguns pontos que considero relevantes. O PROFA, apesar de considerar uma única matriz teórica, ancorada na Psicogênese da Língua Escrita, atribui à formação do formador um status de relevância ao dedicar-lhe, no âmbito do programa, espaço para a problematização de suas especificidades e forma de abordagem do professor em formação, que estão para além dos conteúdos específicos de fundamentação teórica e prática da alfabetização em si.

O Pró-Letramento traz como contribuição a ampliação da articulação discursiva entre variadas demandas em jogo sobre a alfabetização e o letramento, abrindo margens a autonomia do professor, mas, ao mesmo tempo, a enquadra inserindo no processo um dispositivo que funciona potencialmente como regulador da prática do professor - a Matriz de Referência utilizada nas avaliações em larga escala.

A Reorientação Curricular do Curso Normal se orienta por uma racionalidade técnica do currículo, enfatizando a centralidade dos conhecimentos científicos no currículo da formação inicial. O documento, em seu discurso, valoriza a formação do professor pesquisador de sua própria prática sendo esta articulada pela disciplina de Prática Pedagógica e Iniciação à Pesquisa. $O$ aporte teórico tem suas bases na psicogênese da língua escrita, embora insira conteúdos sobre as concepções de alfabetização, os métodos e os processos de desenvolvimento e aprendizagem da leitura e da escrita.

A análise das políticas curriculares permitiu identificar aspectos que contribuem para a reflexão sobre o currículo da formação e seus possíveis avanços. Foram levantados aspectos das políticas de formação continuada que se oferecem como subsídios para repensar a formação inicial do professor alfabetizador. Evidenciamos entre as políticas de formação continuada a tentativa de cerceamento da autonomia do professor, ora por meio da definição restrita da abordagem teórico-metodológica da prática, ancorada na Psicogênese da Língua Escrita, ora por meio das avaliações externas ancoradas nas Matrizes de Referência da Provinha Brasil.

A utilização do modelo de análise proposto por Ball (2009), o ciclo contínuo de políticas, se constituiu em uma contribuição pertinente aos propósitos da análise realizada. Foi observado que os efeitos de diferentes políticas em tempos de globalização exercem força coercitiva significativa, mas não absoluta. Isso significa que diferentes forças disputam concepções sobre a educação, o currículo, a formação de professores e os processos de alfabetização, nos contextos de produção da política, produzindo sentidos. É nesse ponto que 
reside a possibilidade da emergência de novos discursos e a proposição de novos caminhos, sujeitos a novos embates e disputas pelo poder de significar.

Acredito que um grande desafio é tornar discursivamente possível, nas políticas curriculares, o exercício da autonomia dos sujeitos. De modo que as escolhas prévias e inevitáveis na política, não signifiquem o cerceamento do saber, mas a possibilidade de transitar de forma mais autônoma entre os saberes, fazendo avançar os processos de articulação e discursividade nas políticas curriculares.

\section{REFERÊNCIAS}

BALL, Stephen J.; BOWE, Richard. El currículum nacional y su <<puesta em práctica >>: El papel de los departamentos de materias o asignaturas. Revista de Estudios del Currículum. Vol.1, no 2, p.105-13, abril. 1998.

BALL, Stephen J. Um diálogo sobre justiça social, pesquisa e política educacional. Entrevista concedida a Jefferson Mainardes e Maria Inês Marcondes. Educação \& Sociedade, Campinas, vol. 30, no 106, p. 303-318, jan./abr. 2009. Disponível em: < http://www.scielo.br/pdf/es/v30n106/v30n106a15.pdf>, acesso em: 19/02/2014.

BRASIL, MEC/SEF PROFA - Programa de Formação de Professores Alfabetizadores, Guia do Formador, mod.I , Brasília: MEC/ SEF, 2001.

. MEC/SEF PROFA - Programa de Formação de Professores Alfabetizadores, Coletânea de Textos, Volume 3, Brasília: MEC/SEF, 2001 . MEC/SEB, Pró-Letramento, Guia Geral, Brasília: MEC/SEB, 2008. 2001. Relatório de Gestão Financeira - Exercício 2001. Disponível em http://portal.mec.gov.br/seb/arquivos/pdf/sef2001.pdf acesso em 02 de novembro de 2014. CAPOVILLA, Fernando (Org.). Os novos caminhos da alfabetização infantil 2a ed. São Paulo: Memnon, 2005.

FERREIRO, Emília; TEBEROSKY, Ana. Psicogênese da Língua Escrita. Porto Alegre: Artes Médicas, 1985.

INSTITUTO PAULO MONTENEGRO. Indicador de alfabetismo funcional. Disponível em www.ipm.org.br/ipmb pagina.php?mpg=4.0200.00.00\&ver=por, acesso em 14 de novembro de 2013.

MORAIS, Artur Gomes; ALBUQUERQUE, Eliana Correia Borges; Leal,Telma Ferraz (Orgs.). Alfabetização: Apropriação do Sistema de Escrita Alfabética. Belo Horizonte: Autêntica, 2005.

MORAIS, Artur Gomes de. Concepções e metodologias de alfabetização: por que é preciso ir além da discussão sobre velhos métodos? XIII ENDIPE - SIMPÓSIO "OS DISCURSOS E AS NARRATIVAS NOS PROCESSOS EDUCATIVOS", 2006, Pernambuco.

MORTATTI, Maria do Rosário Longo. Notas para uma história da formação do alfabetizador no Brasil. Revista Brasileira de Estudos Pedagógicos, Brasília, v. 89, o 223, pp. 467-476, set./dez. 2008. 
ONU, Res A/56/116 - United Nations Literacy Decade: education for all. 19 december 2001. Disponível em: < http://www.un-documents.net/a56r116.html > acesso em: 11 de dezembro de 2013.

PÉREZ, Carmen Lúcia Vidal. Alfabetização: um conceito em movimento. In: GARCIA, Regina Leite; ZACCUR, Edwiges (Orgs.). Alfabetização: reflexões sobre saberes docentes e saberes discentes. São Paulo: Cortez, 2008.

SEEDUC/SUGEM. Portaria no 91 de 29 de março de 2010. Estabelece normas e orienta quanto a implantação da matriz curricular do Curso Normal em nível médio, e dá outras providências.

SEE/RJ. Reorientação Curricular - Curso Normal, Livro IV, Rio de Janeiro: RJ, 2006.

SMOLKA, Ana Luiza Bustamante. A criança na fase inicial da escrita - a alfabetização como processo discursivo. São Paulo: Cortez/Unicamp, 1988

SOARES, Magda. Letramento: um tema em três gêneros. Belo Horizonte: Autêntica, 2003. 